\title{
DOSSIÎ̂
}

Sociologias, Porto Alegre, ano 17, no 39, mai/ago 2015, p. 198-223

\section{Sociologia moral das dependências motivadas: o caso da dependência amorosa}

\section{Resumo}

Este artigo propõe um panorama do procedimento e dos métodos da sociologia moral, que se baseiam em uma etnofilosofia da existência social comum e em uma antropologia natural. A primeira parte do texto situa a sociologia moral em relação ao desenvolvimento contemporâneo das pesquisas empíricas sobre a ética, sobretudo no âmbito da psicologia experimental e evolucionista. A segunda parte apresenta alguns elementos de uma teoria das dependências motivadas aos prazeres e às recompensas, desenvolvida a partir do aporte das neurociências da adição e de pesquisas de campo sobre as condutas aditivas e as tentativas de restabelecimento. A terceira parte propõe uma ilustração do método a partir de uma pesquisa recente sobre a dependência amorosa, feita principalmente a partir de um corpus literário e cinematográfico.

Palavras-chave: Ética empírica. Etnofilosofia. Dependência amorosa. Condutas aditivas.

* Centre National de la Recherche Scientifique (França)

-Tradução: Patrícia Ramos Reuillard 


\section{Moral Sociology of motivated dependences: the case of love dependence}

\section{Abstract}

This article provides an overview of the procedure and methods of moral sociology that are based on both an ethnophilosophy of common social existence and a natural anthropology. The first part of the text locates moral sociology within the contemporary development of empirical research on ethics, particularly in the field of experimental and evolutionistic psychology. The second part depicts some elements of a theory of motivated dependences on pleasures and rewards, which draws on the contribution of neurosciences of addiction and on field research on addictive behaviors and recovery attempts. The third part illustrates the method by featuring a recent research on love addiction, based primarily on a literary and cinematographic corpus.

Keywords: Empirical ethics. Ethnophilosophy. Love dependence. Addictive behavior.

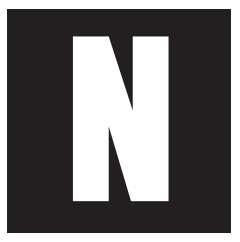

a primeira parte deste texto ${ }^{1}$, situo a sociologia moral entre as pesquisas empíricas contemporâneas sobre a ética (ou a moral'2); na segunda, apresento alguns elementos de uma teoria das dependências motivadas aos prazeres e às recompensas. A terceira parte propõe uma

\footnotetext{
${ }^{1}$ Este texto se inspira em uma comunicação no Seminário Wittgenstein do departamento de filosofia da Universidade Paris 1 Panthéon-Sorbonne, em $1^{\circ}$ de março de 2014. Também retoma elementos de uma conferência no fórum Lundbeck "Cognições morais e construção social" de 27 de março de 2014, no Museu de História Natural de Paris. Tradução de Patrícia C. R. Reuillard (UFRGS).

${ }^{2}$ Como muitos autores, por muito tempo considerei os termos "ética" e "moral" como semanticamente equivalentes. Minha tendência atual, contudo, é preferir o termo "ética" para designar as condutas práticas da vida; o substantivo "moral" remete mais a um corpo de regras ou de doutrina. O adjetivo "moral", tal como utilizado na sociologia "moral", tem em contrapartida uma extensão muito maior: remete a uma postura de espírito relativa ao que é bom ou ruim, livre ou forçado, permitido ou proibido, etc.
} 
Sociologias, Porto Alegre, ano 17, no 39, mai/ago 2015, p. 198-223

ilustração com minha pesquisa mais recente, que diz respeito à dependência amorosa ${ }^{3}$.

\section{Sociologia moral e ética empírica}

O estudo empírico da ética é uma problemática totalmente nova na história das doutrinas morais e se deve em grande parte à Sociologia, que sempre se interessou, desde Comte, Durkheim, Weber ou Parsons, pela dimensão moral dos fatos sociais, ao estudar as normas, valores, razões ou etnométodos que inspiram e organizam as práticas e dilemas sociais.

A sociologia moral que apresento aqui é uma variante de sociologia da ética, que prolonga diretamente a sociologia compreensiva de Max Weber para estudar o sentido das ações humanas em sua dimensão existencial e moral. Contrariamente a outras variantes, ela não se interessa pelas variações socioculturais da moral, cujo conceito e extensão se supõem perfeitamente conhecidos, mas pela definição da própria moral a partir de suas abordagens pelos grupos humanos. Seu campo de estudos se define pelos modos como os sujeitos comuns se situam em relação às coisas e práticas boas ou ruins, belas ou repulsivas, libertadoras ou coercitivas, obrigatórias ou proibidas... da vida social. Seu objetivo é extrair de cada domínio uma espécie de etnofilosofia dos sentimentos, das motivações práticas e do sentido da vida ou, mais especificamente, uma expertise moral mais no sentido passivo (experiência do que é um problema moral) do que normativo (o que fazer). A ideia chave é que as pessoas intimamente envolvidas em uma prática - testemunhas ou até mesmo autores de ficção - são experts, já que o contexto narrativo funciona como esclarecimento e validação de suas análises.

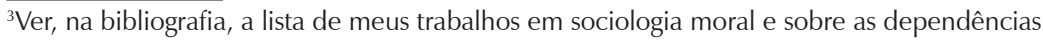


Entretanto, independentemente da linha escolhida, a tradição sociológica de investigação sobre a moral se confronta, hoje em dia, com novas formas de ética empírica que interrogam a origem do sentido moral a partir das reações psicológicas espontâneas observadas durante testes experimentais. Essa nova ética experimental se origina principalmente na psicologia do desenvolvimento (Piaget, Kohlberg, Turiel, Gilligan, entre outros) e na psicologia social pós-guerra, com os trabalhos de Milgram sobre a obediência à autoridade, por exemplo, ou as experiências sobre os fatores situacionais que favorecem ou não o socorro a um ferido. Essas abordagens foram enriquecidas por experimentos mentais imaginados inicialmente por filósofos e depois concretizados em testes experimentais. É o caso do que se chama ironicamente de "problema de trolley", oriundo de um experimento mental proposto pela filósofa Philipa Foot, em 1967, para ilustrar um velho debate escolástico sobre a diferença de intenção entre matar e deixar morrer, ou seja, a doutrina do "duplo efeito", retomada pelas discussões da época sobre o aborto. Um bonde sem freios é lançado em plena velocidade em um trilho onde trabalham vários operários. Pode-se desviá-lo para outro trilho onde se encontra um único operário ou deixá-lo matar os cinco. O que se deve fazer? As respostas geralmente preferidas são utilitaristas (matar um para salvar cinco), salvo quando se substitui, por exemplo, a mudança de agulha pelo empurrão de um homem nos trilhos a partir de uma ponte.

Hoje em dia, a experimentação psicológica frequentemente se acompanha de especulações evolucionistas sobre os precursores do senso moral que podem ser revelados em comportamentos animais ou ancestrais4: a empatia e a generosidade do "bom símio" de F. de Waal, o

${ }^{4} \mathrm{~A}$ obra de N. Baumard (2010) apresenta um panorama muito completo de todas essas pesquisas, acompanhado de uma rica bibliografia, à qual remeto. 
Sociologias, Porto Alegre, ano 17, no 39, mai/ago 2015, p. 198-223

altruísmo de parentesco nos grupos geneticamente próximos (Hamilton), o altruísmo recíproco nas práticas de cooperação (Trivers, Axelrod), a solidariedade e a mutualidade como vantagem adaptativa dos grupos que as praticam, ou certas reações humanas espontâneas, como a compaixão e a simpatia, entre outros. Essas pesquisas coincidem, em parte, com aquelas do intuicionismo filosófico, principalmente o "particularismo", cuja ideia principal é que o julgamento moral em situação real se baseia em intuições espontâneas, independentemente dos princípios. Elas também dão continuidade, de certo modo, às hipóteses dos filósofos britânicos do século XVII - como Hutcheson, discípulo de Shafestesbury -, que consideravam o senso moral como uma espécie de sexto sentido, mais ou menos guiado pelo julgamento racional. Além disso, podem-se utilizar os recursos das imagens cerebrais para pesquisar a localização dos julgamentos morais no cérebro, associando-os a zonas conhecidas por estarem ligadas a processos cognitivos mais ou menos automáticos ou refletidos.

Essas pesquisas sobre os precursores psicoevolutivos do senso moral são particularmente estimulantes e promissoras, mas se chocam com certos limites que a Sociologia conhece de longa data. Um desses limites é o fato de que os comportamentos animais ou ancestrais são independentes do senso moral ou imoral que podemos lhes atribuir a partir das culturas e das doutrinas morais existentes - o que explica, por exemplo, que o altruísmo de parentesco nos seres humanos pareça frequentemente uma forma de nepotismo, e que a seleção de grupo pareça uma forma de compadrio, comportamentos que não soam muito morais. De um lado, a atividade do cérebro associada aos julgamentos morais tem poucas chances de determinar mecanismos cognitivos intrinsecamente "morais", simplesmente porque os julgamentos morais são inseparáveis de seu caráter racional e discursivo, que os torna socialmente abertos, variáveis e revisáveis. Por conseguinte, o fato de saber que um julgamento é mais ou 
menos espontâneo ou refletido conforme sua localização cerebral não diz nada sobre o conteúdo moral ou não moral desse julgamento.

Nessas condições, a hipótese de módulos da moralidade associados a automatismos neuropsíquicos oriundos da evolução natural (por exemplo, o cuidado, a liberdade, a justiça, a lealdade, a autoridade ou o sagrado ${ }^{5}$ ) corre o risco de se chocar com situações em que esses automatismos serão considerados moralmente inadequados ou pura e simplesmente imorais por exemplo, quando uma emoção dita "moral" suscita violências contra os membros de uma etnia ou de uma religião diferentes. $\mathrm{E}$, como o que é considerado obrigatório numa determinada doutrina pode muito bem ser julgado imoral em outra -, por exemplo, não mentir em nenhuma circunstância para se submeter à lei moral, ou sacrificar o destino de alguns indivíduos à felicidade da maioria -, mais vale, de um ponto de vista estritamente lógico, evitar considerar como "moral" o mecanismo cognitivo que subentende um ou outro desses julgamentos! O modularismo psicológico tem, por outro lado, uma propensão exagerada a associar qualquer traço psicológico a supostos automatismos cognitivos inatos; disso decorre, por exemplo, a tendência sexista a buscar traços cognitivos próprios aos comportamentos masculino e feminino, o que ainda é muito controverso. $\mathrm{O}$ contato frequente com as Ciências Naturais e a Etologia, que comprovam a imensa variedade de regras de comportamentos do mundo vivo, deveria, ao contrário, nos precaver contra toda concepção inata ou pré-natal em matéria de ética e de normatividade social ou sexual.

De resto, a genealogia da moral pode muito bem dispensar a complexa hipótese de módulos psicológicos inatos dedicados à moralidade, atendo-se à tese clássica da sociologia durkheimiana, que foi também a de toda a tradição pragmática: o próprio funcionamento da sociedade

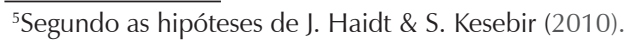


Sociologias, Porto Alegre, ano 17, no 39, mai/ago 2015, p. 198-223

produz moral. De fato, basta observar, nas sociedades históricas ou atuais, as formas de aliança e de vida comum, como o apego e o cuidado com os pequenos, a assistência aos mais fracos, as regras de civilidade para reduzir as ofensas a outrem, ou as imposições do civismo que levam a privilegiar o bem comum ${ }^{6}$, para perceber a ética em estado nascente, por assim dizer. As motivações de todos esses comportamentos "protomorais" quer sejam ancestrais, históricos ou atuais, ainda precisam ser descobertas já que as vantagens adaptativas, como se proteger individualmente, coletivamente, ou sua descendência, também têm com frequência um componente de prazer e de recompensa que sobrepuja o componente estratégico (ver infra). Quanto à ética propriamente dita, no sentido das múltiplas doutrinas religiosas ou filosóficas existentes, ela depende do modo como os grupos humanos vão conceptualizar essas regras e comportamentos em termos de princípios, de virtudes, de valores, de normas, de leis, etc.

No final, o conjunto desses limites deveria, sobretudo nos levar a não avançar muito na hipótese de uma conexão "natural" de nossas faculdades e competências morais para não confundir a ética, no sentido filosófico ou religioso do termo, com funcionamentos cognitivos humanos cuja interpretação moral ou não moral depende, em primeiro lugar, das culturas e das teorias existentes - o que Wittgenstein chamava de "jogos de linguagem".

Todavia, embora a espécie humana não tenha, ao nascer, uma "conexão moral" na cabeça, ela permanece bastante coibida em seus comportamentos básicos - busca de abrigo, de alimentação, de relações sexuais e familiares, de alianças sociais, etc., graças a heranças neurofisiológicas ancestrais -, sendo difícil negar, como fazem as correntes mais antinaturalistas das Ciências Sociais, a validade e a utilidade sociológica

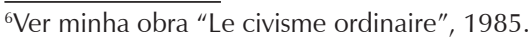

http://dx.doi.org/10.1590/15174522-017003906 
Sociologias, Porto Alegre, ano 17, no 39, mai/ago 2015, p. 198-223

de certas observações do naturalismo darwiniano e das neurociências. Na prática, nada impede adotar aqui uma postura de darwinismo metodológico, que considera e explora os efeitos sociais de mecanismos neuropsíquicos oriundos de funções reprodutivas ancestrais, sem se perder em um darwinismo moral, que substituiria o antigo darwinismo social, hoje desconsiderado.

Esse tipo de postura permite preferir às interpretações da evolução social em termos de revoluções morais ou culturais as explicações mais meramente mecânicas e muito menos interpretativas, fundadas na interação entre disposições neuropsíquicas coletivas ou individuais e condições ecológicas variáveis. Um bom exemplo disso são as condutas aditivas, que se tornaram um fenômeno de massa não devido a um gosto "cultural" pelas drogas, mas a um confronto por parte de um número muito maior de sujeitos com substâncias e práticas de adição facilmente acessíveis pela abertura, ampliação e estimulação constante dos mercados capitalistas. O darwinismo metodológico permite também considerar a evolução pessoal a partir do modelo bem heurístico da boa e da má sorte - isto é, o acaso + a habituação -, que pode ser mais ou menos inflectida pela subjetividade racional. As dependências motivadas ao prazer e às recompensas, que vou abordar agora, são características dessas funções e destinos individuais que podem ser analisados e "eticizados" ${ }^{8}$, ou seja, investidos de um senso moral ou imoral, pela vida social atual.

"Ver, sobre esse tema, minhas duas obras "Philosophie pratique de la drogue" (2011) e "Plaisirs et dépendances dans les sociétés marchandes" (2012).

${ }^{8} \mathrm{O}$ conceito de eticização de práticas que, sem isso, poderiam ser indiferentes à moral, é extraído de F.-A. Isambert (1992). 


\section{As dependências motivadas aos prazeres e às recompensas}

Tal como acabo de apresentar, a sociologia moral é uma sociologia da ação e da existência, que se interessa prioritariamente pelas motivações ao prazer e à felicidade dos sujeitos sociais e pelos finais mais ou menos felizes ou infelizes de seus esforços nesse sentido. Seu método busca na Filosofia seus instrumentos analíticos para decifrar as concepções comuns da existência a partir de testemunhos, entrevistas, autobiografias, ficções literárias ou cinematográficas, etc., visto que o envolvimento direto e pessoal dos sujeitos em situação real e a inscrição de seus problemas morais em sua existência global constituem uma diferença crucial em relação à ética experimental. Ela também busca na Antropologia um postulado de universalismo lógico e de fixação das motivações humanas em disposições originárias da evolução natural. Esse desvio pela Antropologia parece indispensável quando se estudam as dependências humanas básicas, como o consumo, a sexualidade ou o apego.

É esse interesse ao mesmo tempo filosófico e antropológico pelos motores da motivação prática que leva às minhas investigações sobre a filosofia prática da droga, por meio de pesquisas em Paris e Nova York com pessoas que interromperam um consumo severo de heroína, de cocaína ou de álcool, e mais amplamente sobre as dependências motivadas a diferentes práticas aditivas ${ }^{9}$.

Contrariamente a muitos trabalhos em Ciências Sociais que consideram que as Ciências Naturais não têm muito a dizer sobre as condutas aditivas, levei a sério o ponto de vista das neurociências. Ora, um dos principais aportes dessas disciplinas é considerar a adição como uma

\footnotetext{
${ }_{9}^{9}$ Para detalhes de minhas pesquisas sobre essas questões e as referências em estudos sobre adição e sociologia das condutas aditivas, remeto às minhas duas obras citadas.
} 
Sociologias, Porto Alegre, ano 17, no 39, mai/ago 2015, p. 198-223

"doença do cérebro", conforme os termos de Nora Volkow, diretora do $\mathrm{NIDA}^{10}$, em Washington, pois essa "doença" está ligada em particular ao desregulamento do circuito dopaminérgico da recompensa - com modalidades variáveis conforme os produtos. Por exemplo, a não recaptação da dopamina liberada no caso da cocaína. Essa tese um tanto expeditiva pode parecer muito redutora se pensarmos na adição como uma doença puramente orgânica que poderia ser tratada com medicamentos específicos, o que infelizmente não é o caso. Contudo, ela corresponde a uma experiência real dos sujeitos envolvidos, que se sentem vencidos por sua adição, e a um quadro clínico que transcende as fronteiras sociais mesmo que as condições sociais influenciem fortemente as trajetórias de consumo e as chances de cura.

Na verdade, as neurociências da adição oferecem uma espécie de descrição "objetiva" de um sentido natural do prazer e da recompensa, que se revela em todas as práticas sociais com forte intensidade emotiva. Sua abordagem satisfaz, além disso, um critério analítico do prazer, que poderia ser resumido pela palavra "mais!", ou seja, a vontade de recomeçar toda atividade que proporcione prazer - mesmo quando ela também causa sofrimento. Esse critério "mais!" fundamenta tanto a clínica quanto a neurologia das adições, que busca principalmente compreender por que se recomeça apesar das consequências nefastas. Pode-se considerá-lo como uma condição necessária do prazer, ainda que provavelmente insuficiente, já que ele não permite distinguir claramente a busca de um prazer e o alívio de uma dor ou uma compulsão para recomeçar atividades que não proporcionam nenhum prazer - sendo o alívio de uma compulsão, contudo, uma forma degradada do prazer. Em todo caso, o critério "mais!" é suficientemente poderoso para justificar as motivações

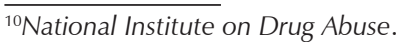

http://dx.doi.org/10.1590/15174522-017003906 
Sociologias, Porto Alegre, ano 17, no 39, mai/ago 2015, p. 198-223

humanas para buscar recompensas sem cessar, inclusive quando elas também têm permanentemente efeitos dolorosos, como o jogo patológico, o alcoolismo ou a heroinomania.

Por outro lado, a busca de prazer é uma reação muito mais primária do que o julgamento moral, e a existência dos circuitos neurológicos da recompensa pode ser documentada não somente nos seres humanos, mas também nos outros mamíferos, pássaros ou peixes. Aliás, foi a partir de pesquisas experimentais iniciais sobre as áreas da vigilância em ratos que as neurociências descobriram, nos anos cinquenta, os mecanismos neuronais dos processos aditivos que, em certas condições de exposição, levam sujeitos animais ou humanos a buscar as substâncias psicoativas a ponto de abandonar qualquer outra atividade, inclusive a sexualidade ou a maternagem, e até mesmo se privar de alimentação. Na abordagem das neurociências, a motivação para consumir está ligada, em um primeiro momento, a um funcionamento normal dos circuitos da recompensa, que são estimulados pela busca dos prazeres associados às substâncias psicoativas ou a práticas como os jogos de azar ou a sexualidade. Será somente a desregulação desse funcionamento normal, relacionada a vulnerabilidades genéticas individuais e às circunstâncias de consumo, em particular o estresse, que vai fazer surgir o quadro clássico das adições: transformação do wanting em craving, perdas de controle, concentração das atividades pessoais somente em torno do consumo, manutenção do comportamento apesar das consequências nefastas, tolerância, sintomas de abstinência...

Essa explicação da adição em termos de desregulação dos circuitos neuronais da recompensa e de disfunção duradoura de diferentes sistemas de neurotransmissão oferece uma base objetiva ao sentimento de impotência do sujeito confrontado ao craving - "é mais forte do que eu!" - e à dificuldade, até mesmo à impossibilidade de retomar uma existência livre de produtos. Ela também permite compreender o parentesco 
entre os efeitos das substâncias psicoativas e os das outras atividades que proporcionam prazer: alimentação, sexualidade, compras, apego, jogos, esporte, trabalho, etc., assim como as transferências de motivação de uma dependência à outra, por simples mudança de objeto. Nas classificações psiquiátricas oficiais (DSM5), o modelo da adição é aplicado diretamente a dependências sem drogas, como o gambling (jogo patológico), e também é evocado para outras dependências, como os videogames ou a hipersexualidade, ou ainda para práticas compulsivas, como o uso da internet, as compras descontroladas e os distúrbios alimentares, que apresentam analogias no plano clínico e neurológico. Essa ampliação combina com a ideia de uma estrutura neuropsíquica da motivação ao prazer oriunda da evolução natural, ativada e eventualmente desregulada por relações, substâncias, hábitos ou ambientes tóxicos.

Uma contribuição ainda mais significativa das neurociências diz respeito à localização cerebral dos mecanismos do prazer, que permite incluir recompensas que não passam pelos órgãos dos sentidos: substâncias ou estimulações endógenas. Esse último ponto indica fortemente um sentido natural do prazer, distinto dos outros cinco, cuja existência parece atestada pela ação direta das substâncias psicoativas sobre o cérebro, colapsando assim os dados dos sentidos. Esse mecanismo rompe com uma longa tradição filosófica que associava o prazer apenas aos dados dos sentidos. Ele permite conceber um prazer "espiritual", "moral" ou "cerebral" por estimulação endógena dos circuitos da recompensa, do tipo alegria com o desinteresse ou com a lei moral, quando se é kantiano, ou com a melhor distribuição dos prazeres, quando se é utilitarista - visto que o prazer é, segundo uma expressão muito sugestiva da neurologista Carole Azuar ${ }^{11}$, uma "moeda única".

\footnotetext{
${ }^{11}$ Paris, Hospital Pitié-Salpétrière, comunicação pessoal.
} 
Sociologias, Porto Alegre, ano 17, no 39, mai/ago 2015, p. 198-223

Hoje em dia, supõe-se que o surgimento e a manutenção desses mecanismos no decorrer da evolução estejam ligados a funções de sobrevivência, pois o fato de ser motivado à sexualidade, à alimentação, à busca de abrigo ou de apego constitui, sem dúvida, uma vantagem reprodutiva. Contudo, o mecanismo atual se tornou independente das funções que o fizeram surgir na história ancestral. Inúmeros trabalhos consideram, aliás, que as substâncias psicoativas "desviam" (hijack) sistemas neurológicos que foram selecionados para fins de reprodução, como substratos de funções sexuais e de apego, e não para fins de consumo de drogas. Em outras palavras, seriam as vantagens reprodutivas da sexualidade e do apego (ver infra) que teriam favorecido o desenvolvimento ancestral dos circuitos da recompensa, cuja estimulação pelas substâncias psicoativas não passaria de um efeito derivado.

A hipótese de um mecanismo neuronal de busca dos prazeres e das recompensas é, em geral, muito bem documentada hoje em dia, embora permaneça uma hipótese científica passível de questionamento ou reformulação - o que já aconteceu, aliás, pois atualmente se considera que o circuito dopaminérgico da recompensa seria mais dedicado ao "wanting" do que ao "liking", ao passo que os mecanismos do prazer seriam muito mais difusos no cérebro. Entretanto, independentemente dos progressos e das revisões científicas futuras, a ideia de uma teleologia individual procedente da causalidade natural e dirigida para o prazer parece bastante robusta em si para fundar uma antropologia. A motivação para o prazer e para a recompensa é, de fato, o resultado, o substrato e o vetor de comportamentos sobre os quais se exerce a seleção natural, enquanto dá um sentido teleológico à experiência de qualquer um. Essa antropologia natural do prazer indica claramente o lugar motivacional de um sentido que pode ou não assumir uma dimensão moral, conforme conteúdos e aplicações oriundos das teorias, das culturas e das políticas morais individuais e coletivas. Ela subentende também um sentido estético que se situa 
Sociologias, Porto Alegre, ano 17, no 39, mai/ago 2015, p. 198-223

em um nível menos elevado do que o da ética na escala da conceptualização axiológica.

Esses trabalhos não dizem nada sobre o conteúdo do senso moral dos seres humanos comuns, quer sejam ou não dependentes, mas permitem compreender melhor certos aspectos axiológicos dos processos aditivos. Por exemplo, a vontade de consumir não é vista como uma fraqueza do ego, menos ainda como uma fraqueza do senso moral dos "drogados", mas, ao contrário, ao menos na experiência inicial, como um poder da liberdade exercida em relação a certos valores e intensidades de vida, antes de se confrontar com limitações dolorosas, precisamente porque os efeitos do mecanismo neuronal passaram a ser incontroláveis.

O modelo adequado das condutas aditivas não é, portanto, aquele frequentemente evocado da akrasia ${ }^{12}$ (intemperança ou fraqueza da vontade), segundo o qual o sujeito julga que $\mathrm{x}$ é melhor do que y (pesando tudo), gostaria então de fazer $x$ mais do que $y$, se for racional, mas ainda assim faz y, que julga menos bom - transgredindo assim um óptimo racional. É claro que esse modelo não está ausente, mas é encontrado sobretudo em uma fase posterior do processo, quando o sujeito tenta controlar ou parar de consumir, mas não consegue - para compreender isso, basta pensar no que ocorre quando se quer comer apenas dois quadradinhos de chocolate e se acaba comendo toda a barra. Em contrapartida, na fase inicial, a da "lua de mel" com o produto, o modelo mais adequado seria, usando os termos de Aristóteles, o da akolasia (autoindulgência): o sujeito julga (ou não) que x é melhor do que y (pesando tudo), mas quer primeiro fazer y e faz y por escolha e por nenhum outro resultado (Ibid., 1150 a 20) - o que lhe permite satisfazer um óptimo motivacional. Nesse esquema de liberdade motivada, o ego não é exterior ao mecanismo de sua moti-

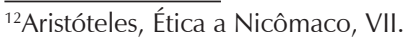

http://dx.doi.org/10.1590/15174522-017003906 
Sociologias, Porto Alegre, ano 17, no 39, mai/ago 2015, p. 198-223

vação, mas se identifica com ele, ao mesmo tempo que se autorreflete: posso fazer isso (mesmo que seja proibido); quero aqui e agora (mesmo que não seja a melhor escolha racional); posso neutralizar as objeções (serão tratadas mais tarde); submeto-me ao destino prático e moral (é o futuro que decidirá).

A entrada deslumbrada e mais ou menos consciente de si mesma em um processo aditivo é frequentemente acompanhada, desde modo, de uma postura de estetização da existência que se exprime por buscas de experiência e de estados superiores em ruptura com a insipidez e a monotonia da vida comum. Essa postura também está presente, porém em menor medida, nas fases de saída, quando se busca um substituto de intensidade equivalente à substância que se tenta deixar. Para justificar essa postura, falo de uma noção de ética da boa vida como expressão moral de nível "intermediário", no sentido de que ela não rejeita forçosamente as morais estabelecidas, mas procura primeiro sublimar a existência individual: com o produto, na fase de autoengrandecimento pela "viagem", ou sem ele, no esforço de desintoxicação.

A ética da boa vida é, por assim dizer, uma moral máxima em relação à sua própria forma de vida, pois ela não pode se satisfazer com meias-medidas ou acordos comuns da existência: é preciso ir ao essencial que é a embriaguez e o high ou, quando se quer sair de uma adição, a renúncia radical à embriaguez, vivenciada então como uma salvação. A ética da boa vida dá, portanto, um lugar central a si mesmo, sem objetivos de egoísmo, mas de autoofuscamento ou de autoengrandecimento - o que é muito mais fácil de conseguir sob o efeito psicoativo de substâncias e práticas intensas do que pelos esforços de abstinência, tais como praticados, por exemplo, nos grupos de autoajuda de tipo doze passos. Pode-se observar, de passagem, que existem, no mundo animal, inúmeros precursores evolutivos dessas éticas da boa vida; por exemplo, nas 
Sociologias, Porto Alegre, ano 17, no 39, mai/ago 2015, p. 198-223

exibições estéticas dos pássaros de Darwin, que mostram ornamentos surpreendentes, apesar dos riscos maiores de predação, para serem escolhidos pelas fêmeas na seleção natural, ou nos pássaros-cetim da Austrália, que decoram seu hábitat com o mesmo objetivo.

Pode-se também observar que a noção de motivação ao prazer, foco desta análise das dependências motivadas, distingue-se bem daquela de pulsão proposta pela psicanálise. Embora o funcionamento dos circuitos da recompensa associados ao wanting evoque diretamente o desejo freudiano de preencher a falta, a motivação ao prazer e às recompensas não pode se reduzir à libido, nem mesmo à pulsão tal como aparece nas diferentes tópicas freudianas (sexual ou de autoconservação, de vida ou de morte). Seu registro é, com efeito, muito mais amplo do que o da pulsão, e seus conteúdos são potencialmente ilimitados. Por outro lado, a motivação está, por definição, sempre presente na mente, e não inconsciente, visto que sua tendência ou seu risco é justamente se tornar obsessiva e compulsiva quando o wanting se transforma em craving. Por fim, a motivação não precisa ser sublimada por uma fantasia ou por um metadiscurso suplementar, pois é espontaneamente sublimada por sua própria dinâmica de intensidade, de "explosão" ou de boa vida. De resto, é porque a motivação ao prazer é espontaneamente sublime que se pode ficar dependente de algo como as drogas ou o amor.

\section{A dependência amorosa}

A análise das dependências motivadas que acabo de apresentar é uma extensão do modelo clínico e neurológico da adição que também pode ser aplicada a dependências comuns que não sejam adições, nem mesmo compulsões, mas que repousam em motivações intensas, passíveis de serem mais ou menos estimuladas ou decepcionadas e, portanto, 
Sociologias, Porto Alegre, ano 17, no 39, mai/ago 2015, p. 198-223

mais ou menos felizes ou infelizes conforme o nível de recompensas obtidas. Foi esse caminho de pesquisa que segui ao estudar as dependências ligadas aos excessos de consumo (compras compulsivas, consumo mídia-político...), mas também as dependências dos idosos e pessoas deficientes, que não são adições, pois impostas inicialmente por uma incapacidade (e não motivadas pela expectativa de uma recompensa), mas que se pode considerar sob o ângulo do craving inerente à privação de mobilidade prática ou de capacidade de cuidar de si mesmo. Foi também esse modelo que utilizei no estudo das dependências cruzadas (ou codependências), como as do dinheiro e do sexo no caso da prostituição ${ }^{13}$.

Atualmente, minha pesquisa se estende à dependência amorosa enquanto consequência potencial e habitual do amor romântico ${ }^{14}$. A pesquisa se baseia em uma ideia frequentemente encontrada na literatura de neurociências ${ }^{15}$, segundo a qual o amor romântico teria uma origem evolutiva dupla: na atração sexual e no cuidado parental. Essa abordagem se fundamenta em observações de imagens do cérebro que mostram que as zonas estimuladas pelo apego parental coincidem, em grande parte, com aquelas implicadas pelo amor romântico, o que confirma observações clínicas e fenomenológicas mais clássicas: de fato, encontra-se o mesmo repertório de gestos, de olhares, de cuidados, de expectativas, de linguagem... no amor romântico e no cuidado parental. Essas observações são completadas por hipóteses relativas às vantagens adaptativas do vínculo afetivo entre os pais para a sobrevivência dos filhos, visto que as funções de cuidado parental podem ser reforçadas pelo vínculo amoroso dos pais.

\footnotetext{
${ }^{13}$ Ver minhas obras "Plaisirs et dépendances dans les sociétés marchandes" (2012) e "Ethica erotica mariage et prostitution" (2013).

${ }^{14} \mathrm{Ver}$ "La dépendance amoureuse Attachement passion addiction" (no prelo).

${ }^{15}$ Para uma revisão da literatura, ver Aron (2005), Leckman (2006), Zeki (2007), Reynaud (2010), Collongues (2011).
} 
Sociologias, Porto Alegre, ano 17, no 39, mai/ago 2015, p. 198-223

Alguns autores (HRDY, 1999), inspirados na teoria do apego de J. Bowlby, consideram também que haveria uma anterioridade evolutiva da satisfação parental sobre o prazer sexual, pois a atração genital evoluiu a partir de uma atração pela aproximação corporal, e não o contrário.

Por outro lado, sabe-se que são os mesmos circuitos dopaminérgicos da recompensa que atuam nas adições às drogas e nas motivações sexual e de apego. Ora, como as funções adaptativas das drogas são a priori muito mais frágeis do que as da sexualidade e do apego, supõe-se que as adições às drogas sejam um efeito derivado e indesejável de um dispositivo motivacional muito mais básico, cuja função inicial é ser escolhido na seleção social e sexual. Nesse dispositivo, o amor romântico dá um lugar crucial às recompensas que emanam de outra pessoa, cuja atitude vai decidir a felicidade ou a infelicidade do apaixonado. No entanto, a dependência amorosa tem mais chances de felicidade do que as dependências às drogas, já que basta que a atração e o apego sejam recíprocos para que a falta possa ser constante e regularmente preenchida. Ela só vira loucura de amor ou adição com seus sintomas habituais - craving, perseguição obsessiva, invasão, persistência dos comportamentos apesar das consequências nefastas, sintomas de abstinência... - quando essa reciprocidade não existe.

O conjunto dessas hipóteses lança uma nova luz sobre a proximidade clínica e neurológica entre as adições às drogas e as paixões amorosas destrutivas, cuja existência havia sido determinada e relatada por inúmeros autores bem antes que se soubesse qualquer coisa sobre as neurociências do prazer e da recompensa. De fato, o poder motivador fora do comum do sentimento amoroso e o potencial aditivo das histórias de amor sempre foram documentados pela literatura, independentemente da origem cultural. É a esse poder motivador que se somam as construções culturais secundárias do amor romântico como a iluminação ou a 
Sociologias, Porto Alegre, ano 17, no 39, mai/ago 2015, p. 198-223

iluminura da existência, ou como alternativa ao tédio e à solidão, desde o mito greco-romano da união imortal de Filêmon e Baucis até à comédia romântica e as paixões incandescentes do cinema contemporâneo, passando pelo rio irresistível e perigoso da Inclinação no Mapa da Ternura de Madeleine Scudery, no século XVII. As comparações interculturais mostram, de resto, que o amor romântico está presente na maioria das culturas $^{16}$, atestado por critérios como os relatos de abatimentos pessoais, o apelo a canções de amor, a existência de fugas amorosas, as narrativas de paixões amorosas e a observação etnográfica (JANKOWIAK; FISCHER, 1992). O amor romântico se revela, deste modo, uma estrutura universal de idealização de uma herança natural estável, que funciona como composição sublimada e unissex de erotismo e de apego, subjacente às emoções amorosas próprias às culturas humanas.

O objeto da sociologia moral diz respeito precisamente às implicações sobre as práticas atuais de uma herança evolutiva caracterizada pelo que se chama, em etologia, de "seleção sexual", isto é, a escolha de um parceiro sexual (frequentemente exercida, aliás, pelas fêmeas em direção aos machos): escolhem-se aqueles que se ama eroticamente, esperando também ser escolhido, e pela seleção parental, pois escolhemos aqueles a quem podemos nos apegar como a um genitor ou filho. Essa herança se encontra na maioria dos testemunhos que estudei, principalmente naqueles das ficções cinematográficas e literárias, sob as múltiplas formas do ciúme e do medo de perder o ser amado. Essa questão crucial da escolha de si mesmo pelo parceiro explica a importância, na experiência subjetiva, do fantasma do terceiro como chance de ser escolhido, apesar da concorrência, por um ser cuja escolha poderia também recair sobre

\footnotetext{
${ }^{16}$ Conforme a amostra intercultural standard estabelecida pela revista "Ethnology" desde 1969 e depois aperfeiçoada (MURDOCK, 1969).
} 
Sociologias, Porto Alegre, ano 17, no 39, mai/ago 2015, p. 198-223

outra pessoa. Na obra citada, examino em particular a expertise da dependência amorosa revelada pela obra de Marcel Proust (1999), “Em Busca do Tempo Perdido". Um de seus maiores objetivos é mostrar o vínculo entre a dependência amorosa e a atração do(a) amado(a) por um terceiro radicalmente inimitável: o narrador tem ciúmes dos amores homossexuais de Albertine, impossível de igualar, já que ele é um homem - do mesmo modo que, na vida real, Proust tinha ciúmes dos amores heterossexuais de Alfred, seu motorista, que ele era incapaz de imitar pois era, mais uma vez, um homem! Contrariamente à tese clássica de René Girard (1961), que via no terceiro uma garantia mimética do valor social do(a) amado(a), a abordagem pela dependência motivada ressalta sobretudo a capacidade amorosa e a alteridade radical do ser amado como condição de sua própria dependência: é porque ele (ela) pode amar um outro que o amor do amado(a) tem tanto valor, mesmo que seja parcial, efêmero ou intermitente.

É também esse confronto com a alteridade radical do ser amado que explica os mecanismos de posse e de submissão recíproca, que não passam da consequência do gozo esperado caso o outro o prefira. A falta de certeza sobre a disposição do outro determina o valor crucial que lhe é atribuído: só possuímos o que depende da vontade do outro ao qual nos submetemos; se a vontade do outro desaparece, não temos mais nada para possuir e mais nada para desejar nem amar - ou, segundo um comentário de Madame de La Fayette acerca do Príncipe de Clèves e de sua esposa: Mesmo sendo seu marido, ele não deixou de ser seu amante porque tinha sempre algo a desejar além da posse (LAFAYETTE, p. 69). Mais especificamente ainda, parece que o que se ama na dependência amorosa é o gosto do(a) amado(a), ideia muito bem expressa pelo que se poderia chamar de princípio de Heloísa: 
Sociologias, Porto Alegre, ano 17, no 39, mai/ago 2015, p. 198-223

Ainda que o nome de esposa pareça mais sagrado e mais forte, eu teria preferido para mim o de amiga, ou até mesmo, sem querer chocá-lo, o de concubina e de puta no pensamento, e mais humilde eu me faria para ti, mais eu adquiriria títulos para tuas boas graças, e menos eu afetaria o glorioso brilho de tua genialidade (Carta de Heloísa a Abelardo, p. 117).

Na concepção de Heloísa, ser a puta de seu amado - ou "o" puto, generalizando a observação e incluindo o masculino - seria a manifestação mais certa do amor, pois amar é amar o gozo e o bem-estar, até o narcisismo de outrem.

Isso posto, e contrariamente às abordagens filosóficas do amor, a sociologia moral não precisa escolher entre todas as teses existentes sobre a natureza do amor, nem ser convencida pelas objeções levantadas contra cada uma delas. Se consultarmos, por exemplo, o excelente artigo da "Stanford Encyclopedia of Philosophy" sobre o amor (HELM, 2013), veremos que as quatro tendências filosóficas arroladas - o desejo de união com alguém, que cria o paradoxo da união versus autonomia; o interesse especial por alguém, que leva a privilegiar seu próprio bem-estar em detrimento da autonomia; a valorização de alguém por apreciação de suas qualidades intrínsecas ou por atribuição de qualidades; a emoção própria ou complexa ligada a uma relação com o ser amado - podem ser todas satisfeitas por aspectos realmente observáveis do sentimento amoroso. Ora, apesar das objeções principalmente normativas levantadas no artigo, parece muito difícil arruinar analiticamente uma teoria particular do amor, mesmo quando ela parece muito distante do sentido mais imediato, pois se pode muito bem oprimir, torturar, matar... por amor. A única atitude analiticamente excluída é a indiferença.

Em compensação, a sociologia moral está muito mais interessada nas expressões do mesmo problema filosófico encontradas nos testemu- 
Sociologias, Porto Alegre, ano 17, no 39, mai/ago 2015, p. 198-223

nhos reais ou literários, que frequentemente opõem uma posição realista (são as qualidades do ser amado que fazem com que seja amado) a uma posição construtivista (a disposição a amar se "cristalizaria", conforme a noção de Stendhal, em um ser qualquer), ou a uma posição racional (o amor seria o resultado de uma história relacional). Esses três polos - objetividade, construção, relação - são existencialmente cruciais na literatura e nos testemunhos porque indicam a incerteza intrínseca do sujeito diante das razões, com frequência incompreensíveis, que levam à sua dependência. Por exemplo, o narrador do romance de Marcel Proust, submetido ao que chama de "intermitências do coração", debate-se permanentemente entre estas hipóteses: "eu a amo porque estava disposto a amar uma mulher que tivesse mais ou menos as mesmas qualidades", mas também "eu a amo porque era ela, e unicamente ela", teses que são finalmente absorvidas pela história da relação de Marcel e Albertine. Na observação das condutas amorosas, o problema filosófico se dissolve em uma fenomenologia dos componentes de formas, de odores, de gostos naturais e sociais, de trajetórias particulares, etc., que alimentam os testemunhos e as ficções sobre o que significa amar.

A sociologia moral tampouco está diretamente interessada em uma justificativa ética específica ao amor, mas, sim, na questão de sua compatibilidade com a ética comum. Essa compatibilidade parece altamente desejável, se pensarmos que a ética é muitíssimo importante: o que implica, por exemplo, respeitar o ser amado, ou não lhe fazer mal, mas ela nem sempre está garantida nos amores reais, porque este é um domínio em que se pode muito facilmente prejudicar os outros ou a si mesmo. Ora, quando fazemos mal a nós mesmos ou aos outros, tanto no amor quanto nas drogas, as lições de moral de nada servem. Tudo o que se pode dizer no plano normativo é que seria melhor se precaver contra amores tóxicos (mas é fácil dizer...), ou que se deveria questionar a própria con- 
Sociologias, Porto Alegre, ano 17, no 39, mai/ago 2015, p. 198-223

duta quando se tem uma relação tóxica, como fazem, por exemplo, os membros dos Dependentes Sexuais e Afetivos Anônimos (DASA) ${ }^{17}$, que investiguei em Paris. Uma relação tóxica é uma relação que faz mais mal do que bem e que, por consequência, contradiz o senso comum de que é melhor se fazer bem do que mal. Os dependentes buscam os DASA exatamente porque acham que evitar o sofrimento da primeira pessoa, além daquele de outrem, tem um valor muito alto - no mínimo, evitar a morte (que sempre é uma eventualidade nas histórias de amor) - e porque buscam um jeito praticável de realizar esse valor. Como nos outros grupos de Doze Passos, esta é, na verdade, uma forma de perfeccionismo moral que leva a buscar alternativas para a autodestruição junto aos pares.

A dependência afetiva ou amorosa é, em todo caso, um bom exemplo de passividade da ética: as pessoas passam por situações de conflito, de dilema ou de sofrimento, que às vezes elas próprias buscaram, como as drogas e o amor, mas não querem as consequências tóxicas, às quais tentam se adaptar ou se extrair. De modo mais geral, o exemplo da irmandade DASA confirma de maneira gritante a ineficiência das argumentações éticas de princípio nas questões sensíveis. Vê-se isso, por exemplo, nas justificativas contemporâneas de um modo ético de conduta da vida amorosa, que por vezes invertem o modelo conservador da monogamia, opondo-lhe o dos amores plurais. Porém, supondo que um personagem como o do ator Charles Denner, no filme de François Truffaut "O Homem que Amava as Mulheres"18, tenha uma "verdadeira" justificativa ética para seu comportamento de "mulherengo", isso não diminuiria nada do problema do sofrimento dos perdedores na corrida ao amor. Inversamente, o

\footnotetext{
${ }^{17}$ Ramificação, na França, dos Sex and Love Addicts Anonymous americanos. No Brasil, os D.A.S.A, Dependentes de Amor e Sexo Anônimos, seguem a mesma linha.

${ }^{18}$ França, 1967.
} 
Sociologias, Porto Alegre, ano 17, no 39, mai/ago 2015, p. 198-223

sofrimento do abandonado jamais é uma objeção ética categórica a este ou àquele comportamento, embora permaneça frequentemente uma objeção hipotética que muitas pessoas se fazem no momento de escolher, como se vê nas pesquisas e na literatura sobre o assunto.

O amor é um risco, como sabia muito bem a Princesa de Clèves, visto que é por isso que se recusa a se casar o duque de Nemour, um mulherengo que pode muito bem lhe ser infiel mais tarde. Mas esse risco é dificilmente uma justificativa moral categórica para um tipo de conduta amorosa, quer se trate do libertarismo extremo pregado por Mathieu Lindon (2011) que, ao narrar seus amores e sua vida com Michel Foucault, julga "a exigência de fidelidade uma vergonha", ou do "conservadorismo radical", que o realizador Éric Rohmer parece, ao contrário, defender na série dos "Seis Contos Morais"19, que terminam todos por uma escolha única em amor - confirmando assim a escolha principal de fidelidade nas relações monogâmicas ditas seriais ou sucessivas, modelo dominante atual, segundo as pesquisas ${ }^{20}$. É difícil imaginar, de fato, como se poderia decidir em princípio esse tipo de questão.

Seja como for, este não é o objeto da sociologia moral, que só se interessa pelo perfeccionismo moral como dado de pesquisa: as pessoas são frequentemente perfeccionistas que querem se modificar para escapar a certos sofrimentos da dependência. Outro dado de pesquisa pelo qual se interessa a sociologia moral é o existencialismo moral, no sentido de uma tentativa incessante de domesticar os dilemas e as dificuldades da relação consigo mesmo e com outrem. A única conclusão ética a tirar dos exemplos reunidos nesses trabalhos diria respeito aos êxitos e aos revezes

19“A Padeira do Bairro" (1963), "A Carreira de Suzanne" (1967), "A Colecionadora" (1967), "Minha Noite com Ela" (1969), "O Joelho de Claire" (1970), "Amor à Tarde" (1972).

${ }^{20}$ Ver "La sexualité en France, pratiques, genre et santé" (BAJOS, N. ; BOZON, M..2008). 
Sociologias, Porto Alegre, ano 17, no 39, mai/ago 2015, p. 198-223

de uma norma (aristotélica) de busca da felicidade inerente ao comportamento humano: essa norma alimenta a ética da boa vida, em suas formas mais incandescentes, tanto quanto as tentativas de reparação do que deu errado, com o auxílio dos pequenos recursos do existencialismo moral.

Patrick Pharo - Doutor em Sociologia (Paris VI), Doutor em Ciências Humanas (Ecole des Hautes Etudes en Sciences Sociales, ex-diretor do Centre de Recherche Sens Ethique Société, diretor de investigação do Centre National de la Recherche Scientifique. patrick.pharo@parisdescartes.fr

\section{Referências}

1. ARISTÓTELES. Ética a Nicômaco.

2. ARON, A.; FISHER, H. et al.. Reward, Motivation, and Emotion Systems Associated with Early-Stage Intense Romantic Love. In: Journal of Neurophysiology, n 94, 2005.

3. BAJOS, N. ; BOZON, M.. La sexualité en France, pratiques, genre et santé. Paris: La Découverte, 2008.

4. BAUMARD, N.. Comment nous sommes devenus moraux. Paris: Odile Jacob, 2010.

5. BOUYÉ, E. (ed.). Abélard et Hélö̈se, Correspondance, 1132-1133. tr. fr. O. Gérard, pref. de E. Gilson. Paris: Gallimard, 1938.

6. COLLONGUES, N. et al.. Amours et neurologie, L. In : Revue neurologique, $\mathrm{n}^{\circ} 167,2011$.

7. FOOT, P.. The Problem of Abortion and the Doctrine of the Double Effect. In: Virtues and Vices, Oxford Review, n 5, 1967.

8. GIRARD, R.. Mensonge romantique et vérité romantique. Paris: Grasset, 1961

9. HAIDT, J.; KESEBIR, S.. Morality. In: FISKE, S. et al. (eds.). Handbook of Social Psychology. 2010, p.797-832.

10. HELM, B.. Love. In: ZALTA, E.N. (ed.). The Stanford Encyclopedia of Philosophy, ed. 2013.

11. HRDY, S.. Mother Nature: A History of Mothers, Infants and Natural Selection. New York: Pantheon, 1999.

http://dx.doi.org/10.1590/15174522-017003906 
Sociologias, Porto Alegre, ano 17, no 39, mai/ago 2015, p. 198-223

12. ISAMBERT, F.-A.. De la religion à l'éthique. Paris: Cerf, 1992.

13. JANKOWIAK, R.; FISCHER, E.F.. A cross-Cultural perspective on romantic love. Ethnology, vol. 31, n², 1992.

14. LAFAYETTE, Madame de. La princesse de Clèves, 1678. Paris: Livre de poche, 1999.

15. LECKMAN, J.F., HRDY, S.B et al.. A biobehavioral model of attachment and bonding. In: STERNBERG, R.. The New Psychology of Love. New Haven \& London: Yale UP, 2006.

16. LINDON, M.. Ce qu'aimer veut dire. Paris: P.O.L., 2011.

17. MURDOCK, G.P.; WHITE, D. R.. Standard Cross-Cultural Sample. In: Ethnology. vol. 9, 1969.

18. PHARO, Patrick. Le civisme ordinaire. Paris: Méridiens - Klincksieck, 1985.

19. PHARO, Patrick. Morale et sociologie, le sens et les valeurs entre nature et culture. Paris: Gallimard, folio, 2004.

20. PHARO, Patrick. Raison et civilisation, Essai sur les chances de rationalisation morale de la société. Paris: Cerf, 2006.

21. PHARO, Patrick. Philosophie pratique de la drogue. Paris: Cerf, 2011.

22. PHARO, Patrick. Plaisirs et dépendances dans les sociétés marchandes. Bruxelles: Éd. de l'université de Bruxelles, 2012.

23. PHARO, Patrick. Ethica erotica mariage et prostitution. Paris: Presses de SciencesPo, 2013.

24. PHARO, Patrick. La dépendance amoureuse Attachement Passion Addiction, no prelo.

25. PROUST, M.. A la recherche du temps perdu, 1913-1927. éd. J.-Y. Tadié. Paris: Quarto, Gallimard, 1999.

26. REYNAUD, M.. L'addiction amoureuse existe-t-elle? In: Annales MédicoPsychologiques, $n^{\circ} 168,2010$.

27. ZEKI, S.. The neurobiology of love. In: FEBS Letters, $n^{\circ}$ 581, 2007.

Recebido em: 10/09/2014

Aceite Final: 10/01/2015 